\title{
Countermeasures of National Culture in the Context of Cultural Globalization
}

\author{
Cheng Chen, Xuecheng Wang, Fei Chen* \\ School of Humanities and Information Management, \\ Chengdu Medical College, \\ Chengdu, China \\ *Correspondence: happycc886@126.com
}

\begin{abstract}
While the pace of globalization is speeding up, cultural globalization comes into being. In the wave of cultural globalization, the survival and development of national culture have attracted increasing attention and discussion, which has built the time background for the "going out" cultural strategy. The Belt and Road Initiative promotes in-depth communication in economy, trade and culture among countries along the route, aiming at integration and common development. Therefore, in the multicultural collision environment, facing the impact of foreign culture, how to develop national culture has become a hot issue. In the face of the "double-edged sword" of cultural globalization, the right concept should be openness and inclusiveness, diversity and coexistence, mutual respect and learning, as well as common development. On the premise of sticking to both the nationalization foundation and globalization orientation, and under the guarantee of improving cultural policies, the strategy of organic and dynamic integration of domestication and foreignization is considerably necessary in translation activities, involving different languages and cultures, so as to promote national culture to go out smoothly.
\end{abstract}

Keywords-Cultural globalization; national culture; cultural and language strategies; translation strategies

\section{INTRODUCTION}

In today's world, globalization has become an irresistible world trend, involving economy, politics, science and technology, culture and other aspects. Due to the accelerating pace of communication, collision, integration and multiinteraction among various national cultures in the world, cultural globalization and its influence on the development of national native culture have attracted extensive attention from the academic circles at home and abroad. In recent years, with the increase of the proportion of Chinese-foreign translation, the strategy selection of translation, a cross-language and cross-cultural communication activity, is also a problem worth discussing in the context of cultural globalization.

\section{Cultural Globalization AND nAtional Culture}

\section{A. Cultural Globalization}

Globalization firstly manifests itself as economic globalization, and then is followed by cultural globalization, political globalization and so on. Although there are still some debates on these two issues of "what is cultural globalization?" and" is there cultural globalization?” [1], most scholars agree

This work was supported by the fund from Sichuan Foreign Language and Literature Research Center (No. SCWYH14-05). that cultural globalization is a large-scale human cultural activity, including languages, thoughts, customs and other elements. Cultural globalization is the product of the development of human society at a certain stage. It changes with the transition of history and promotes the progress of science and technology as well as the development of productive forces.

\section{B. Relationship between Cultural Globalization and National Culture}

In terms of the relationship between cultural globalization and national culture, the former is based on the latter while exerting a profound influence on the latter. As is known to all, culture is the accumulation of national psychology and the basic form of people's life formed in history. Cultural globalization promotes the communication and integration of native cultures of various nationalities and provides a broad space for the prosperity and development of these native cultures. At the same time, the rapid advance of globalization also causes some native cultures to be lost and displaced. Since globalization is often considered as an attack on the national spirit or personality, it constantly causes cultural anxiety [2]. Under the "double-edged sword" of cultural globalization, any national culture can not only absorb the advantages of foreign culture, but also obtain its own development and form cultural identity in a broader sense. It may also face tests and challenges, encounter development obstacles, or even be eroded by a strong culture and lose its own living space. Due to different characteristics, in the process of cultural communication, friction, conflict and even exclusion of various national cultures are inevitable; while at the same time, they learn from each other, supplement each other and promote each other. In the face of the strong influence of foreign cultures, especially the dominant western cultures, what appropriate countermeasures should the national culture adopt?

\section{Two Extreme Cultural Views}

Two moderately extreme cultural views are ethnocentrism and national nihilism. Ethnocentrism overemphasizes the cultural characteristics and advantages of its own group, denies or despises other cultures, and even refuses to communicate with others. Ethnocentrism holds that there is neither possibility of equal communication with other cultures nor the necessity of mutual integration. Arbitrarily rewriting 
the culture of others and strongly advocating the adoption of domestication strategy in translation are the manifestation of ethnocentrism. National nihilism, on the contrary, ignores national characteristics, denies national cultural traditions and historical heritage, and holds that national culture is useless and cannot keep pace with the development of times, so it needs to be thoroughly transformed by foreign culture. It has no confidence in national culture, and even negates its own culture and chooses to attach itself to the influential western culture. As a matter of fact, the expansion of the western developed capitalism has formed a strong impact on native cultures of various ethnic groups in developing countries, gradually making these cultures as the appendage of western culture, thus resulting in the identity crisis of some national cultures. The strategy of extreme foreignization in translation is a demonstration of national nihilism. It turns out that any extreme view of culture can hinder cultural communication [3], [4].

\section{CORRECT CUlTURAL VIEWPOINT AND CHINA'S CUlTURAL AND LANGUAGE STRATEGIES}

\section{A. Correct Cultural Viewpoint}

The process of cultural globalization should contain respect for cultural diversity because globalization and nationalization are not binary opposites. It is difficult for any national culture to develop in isolation and self-seclusion. In the process of globalization, national culture develops and evolves constantly, adjusts itself to the new environment, and forms cultural integration with foreign cultures. Foreign cultures are also actively adapting to the local atmosphere, looking for a foothold. In today's world of increasingly close cultural communication, the basic elements of culture, such as customs, ways of thinking, values and so on, are all influenced by the outside world. The two sides contain each other and inextricably interwoven with each other. Participants in cultural communication should be aware of the fact that diverse cultures coexist, and should treat foreign cultures with an open and inclusive mind, instead of blindly rejecting them. At the same time, participants should be full of confidence in the national culture, maximize its strengths, get rid of its weaknesses, and seek lasting development. Traditional Chinese culture, represented by Confucian culture, has always emphasized that "the sea is vast and inclusive". Its fundamental characteristics are "harmony" and "inclusiveness" and it emphasizes "harmony without uniformity" and "nothing is incompatible". This makes the Chinese culture not only achieve complementarity within its own range, but also have the premise of complementarity with foreign cultures [5]. This is also a reflection of the cultural viewpoint of China since ancient times.

\section{B. China's Cultural Strategy}

The prosperity of a country or a nation is always supported by the prosperity of its culture. The great rejuvenation of the Chinese nation requires the development and prosperity of Chinese culture. Cultural prosperity and development is a country's deepest soft power, and is an important part of a country's comprehensive national strength, because culture is the soul of a country and a nation. When a country's culture is prosperous, the country is prosperous. When the cultural soft power of a nation is strong, the nation is strong. It is said in the report to the 19th National Congress of the Communist Party of China (CPC) that we need to strengthen cultural confidence and ensure the prosperity of socialist culture. It is said that there can be no great rejuvenation of the Chinese nation without a high degree of cultural confidence and cultural prosperity. We must adhere to the path of socialist cultural development with Chinese characteristics, stimulate the cultural innovation and creativity of the whole nation, and build a strong socialist cultural country [6].

Over the past period of time, cultural confidence has been enhanced, China's cultural soft power and the influence of Chinese culture have been greatly enhanced, and the brilliant traditional Chinese culture nurtured by the Chinese civilization of more than 5,000 years has been spread in many parts of the world. All these are closely related with China's cultural strategy of "going out". At the beginning of the 21st century, China put forward the cultural construction policy of "going out", and tried to carry forward the Chinese culture on the premise of adhering to the Chinese culture foothold. Since the 18th national congress of CPC, China has launched policies to promote cultural "going out" and published a series of documents to promote cultural communication and spread. Stimulated by this strategy, Chinese literary works were gradually translated and introduced to foreign countries, and became popular. Mo Yan, Liu Cixin, Cao Wenxuan and others successively won international literature awards, many Chinese films and TV programs gain popularity abroad, and Chinese traditional folk arts and dramas are favored by foreign audiences, all of which are evidence of the achievements of cultural "going out" strategy.

Since the Belt and Road Initiative was put forward, more and more countries have actively participated in its construction, and cultural communications have gradually increased and the forms to spread culture have become increasingly diversified. In view of the different forms of civilization in countries along the Belt and Road route, China calls for promoting cultural communication and cooperation among countries on the basis of seeking common ground while reserving differences, fully respecting the cultural traditions of other countries, resolving cultural conflicts through equal dialogue and consultation, maintaining cultural diversity, learning from each other, and viewing cultural diversity with an open and inclusive mind.

\section{China's Language Strategy}

Take the Belt and Road Initiative as an example. There are 53 official languages in the 65 countries along the Belt and Road route, forming the most prominent region with the richest language diversity and cultural differences in the world, which highlights the importance of translation. It strongly demonstrates once again that language is an important link for communication and mutual learning among cultures and civilizations, and that effective translation strategies and highquality translation play an important role in improving the cultural soft power of a country and promoting cultural communication and cooperation. To make a good plan for the Belt and Road language strategy, to balance the multi- 
language interests and to achieve language connectivity of countries along the route are the challenges that must be faced and dealt with in the construction of the Belt and Road. They are also some important guarantees to promote steady progress of the initiative. Handling the important relationships between language and culture and some other factors is conducive to the spread of Chinese language and culture, which also helps to ultimately realize the strategic goal of overall connectivity through language connectivity.

The construction of the Belt and Road further promotes the birth of language demand, and language plays an increasingly important role in promoting Chinese culture to "go out". Serving the construction of the Belt and Road has become an important aspect of the language and culture work in China. Examples are listed as follows. The fever for Chinese language keeps increasing in countries along the route. The number of people who learn Chinese has risen significantly, and the pace of Chinese language "going out" continues to accelerate. China has signed agreements with many countries along the route to translate each other's literary classics. Confucius institutes have grown in countries along the route.

As China gradually steps towards the center of the world stage, to promote the spread of Chinese language worldwide and the "going out" of Chinese culture not only conforms to the desire of the international community to further understand China, which increases the affinity and attraction of Chinese culture, but also meets the objective requirements that we need to maintain language and cultural diversity in the era of globalization, hold a more open mind in the face of other cultures, actively absorb the excellent achievements of human civilization, and show an image of a responsible big country. Therefore, it is necessary to fully grasp the rules of Chinese language spread and cultural communication and strengthen the international communication ability and the construction of discourse system in publicity. It is also necessary to deeply explore the language and cultural resources of countries along the route in order to wonderfully tell stories about China and about the common development of countries and regions along the route. We should contribute to cultural heritage and spiritual communication based on language connectivity, and give full play to the important role of the Belt and Road language strategy in promoting the construction of the community of shared future for mankind.

Language and culture merge with each other. To build the Belt and Road, we should understand not only the languages of countries along the route, but also the customs, historical traditions, social psychology, cultural awareness, religious beliefs and ethnic relations hidden behind the languages. Besides, we should grasp the cores of their ideologies and values on the basis of understanding their cultures so as to realize the path evolution from language to culture, from characters and letters to thought, and from concept to emotion; thus realizing in-depth people-to-people connectivity. This highlights the importance of translation, and reveals that effective translation strategies and high-quality translation do play an important role in promoting language and cultural communication and cooperation.
IV. StRategy SELECtion IN THE PUBlicity TRANSLAtion OF NATIONAL CULTURE

\section{A. Cultural Turn in Translation Studies}

Undoubtedly, cultural differences increase the difficulty of translation. As a bridge of cultural communication, it is really difficult for the translation to faithfully convey information and effectively promote mutual understanding between different cultures. With the promotion of globalization and the advancement of the Belt and Road, cultural communication activities become more and more frequent, which increases the requirement for translation to some extent. Adapting to globalization without losing its native features is an important issue for translation. Every national culture has its own unique way of expression, which embodies historical experience and cultural accumulation. If only the words and images are analyzed and processed in translation, cultural connotation cannot be conveyed. Only by involving in cultural elements and valuing the investigation of cultures of both the source language and target language can we hope to achieve the language conversion and cultural communication. Therefore, in the context of cultural globalization, cultural turn in translation studies is imperative. Translation needs to get rid of the shackles of words and turn into the interpretation of cultural connotation and pay attention to the interactive relationship between the source language and the target language. In cultural communication activities, both the literal meaning and the cultural meaning of the source text need to be presented through cultural translation. Therefore, cultural translation should not only fully reflect the native characteristics, but also adapt to the development trend of globalization, which is the result of the mutual communication and integration of globalization and nationalization, as well as the requirements of the times.

\section{B. Selection of Translation Strategies}

Translation, as a bridge of communication, plays a considerably important role in cultural communication. How to deal with cultural factors in translation is often a headache for translators. As is widely known that the choice of cultural standpoint and cultural perspective are directly related to the translation effect, the identification of national culture and the establishment of national humanistic image. Therefore, translators often hesitate between domestication and foreignization. Domestication believes that translation should be the target language readers oriented in order to be smooth, readable, and more suitable for the target language readers. This is actually a suppression and rewriting of the other culture so as to achieve the goal of consolidating the native culture. Foreignization advocates that translation should be source language author oriented and the characteristics of the source language culture should be preserved as far as possible so that the target language readers can enjoy the exotic atmosphere. This will cause other cultures to compete with, or maybe eventually replace, native cultures. Although domestication and foreignization have opposite sides, they are unity of opposites. Therefore, it is necessary to deal with the relationship between them dialectically and scientifically. 
In the context of globalization, the publicity of national culture can be regarded as a competition between national culture and foreign culture, which, from a macro perspective, is closely related to economic, political, cultural, social, historical and other factors. In modern and contemporary translation studies, "foreignization translation", which shows differences, has attracted much attention. However, with the "going out" cultural strategy, the purpose of translating materials, which are rich in national cultural factors, is to promote national culture to go out and expand its influence. From this perspective, it seems that translation should strive to be fluent and exquisite in language so as to achieve acceptance in the target language culture [7]. In fact, the key role translation plays in promoting globalization and nationalization lies in its recognition of the value of other cultures and its recognition of the limitations of national culture [2]. Experience and facts have proved that as the inheritors and promoters of Chinese traditional culture, translators should analyze specific translation problems on a case-by-case basis. We should adopt the strategy of foreignization to introduce in the excellent factors which are beneficial to the construction of national culture. For the backward factors that may have a negative impact on the national culture, we should adopt the domestication strategy to reduce them. In this way, by introducing new and dynamic elements through translation, the innovative resources of national culture will not be exhausted. At the same time, reducing the unfavorable factors of other cultures can also avoid the possible damage to the national culture and ensure the inheritance and development of the excellent national cultural elements [3]. Thus, by organically integrating domestication and foreignization according to specific conditions, by seeking a balance between national culture and foreign culture as much as possible, by learning the essence of foreign culture and by developing the advantages of national culture, the ultimate goal of translation can be achieved and effective cultural communication can be realized.

\section{CONCLUSION}

When realizing that the going out of Chinese traditional culture which bears the core value of China is the only way to build a strong socialist culture, we should understand that while cultural globalization is booming today, we should advocate cultural diversity, get rid of cultural discrimination and prejudice, and learn from the advantages of foreign cultures while maintaining the uniqueness of national culture and highlighting its advantages. In the context of globalization, we should not only see opportunities but also risks brought by cultural globalization. In the communication and collision between national culture and foreign culture, national culture confronts with not only the opportunity of going out to the world, but also the risk of losing its individuality. Fortunately, with the advancement of cultural globalization, national culture and foreign culture interact with each other, gain recognition and joint development. Many scholars believe that the interaction between globalization and nationalization will largely determine the development trend of world culture in the future. In the tide of globalization, it is the best choice for national culture to treat foreign culture with an open and inclusive attitude, seek foothold and survival and development space in opportunities and risks, strive for equal interaction with foreign culture, and achieve harmonious development.

Translation has built an important bridge for cross-cultural communication. Translators should actively adapt to and participate in cultural communications. Translators should not only absorb the nutrition beneficial to the national culture, but also defend the uniqueness of local culture. In the cross-border activities of cultural translation, we should treat language as the medium and adopt the strategy of a dynamic integration of domestication and foreignization so as to inherit and carry forward national culture and adhere to its individuality. At the same time, we should absorb the essence of other cultures to promote our own development, advocate diversity and tolerance, and promote cultural sharing and common prosperity.

\section{ACKNOWLEDGMENT}

The deepest gratitude should be given to Xuecheng Wang, who gave much guidance and provided abundant referring materials.

The sincere appreciation should also be given to Fei Chen for her support to this paper and the inspiration obtained from her research project: A Corpus-based Study of English Abstracts of International Medical Academic Papers from Perspective of Functional Linguistics.

\section{REFERENCES}

[1] Z. Senlin, "Culture globalization: chance and challenge for ational culture,” Journal of Northeast Normal University (Philosophy and Science), Changchun, no. 5, pp. 70-74, May 2007.

[2] S. Yifeng, "Cultural translation and glocalization,” Chinese Translators Journal, Beijing, no. 1, pp. 5-11, May 2008.

[3] Z. Ningqi, and C. Yafei, "Translation and native culture in the context of globalization,” Journal of Yangtze University (Social Sciences), Jingzhou, vol. 33(1), pp. 179-180, Feb., 2010. (In Chinese)

[4] L. Qing, “The conflict between cultural globalization and national culture and its countermeasures," Journal of Shangdong Yourth University of Political Science, Jinan, vol. 30(5), pp. 23-25, Sep., 2014.

[5] Z. Yue, "Integration of localization and globalization-An Analysis of the Problem of Chinese Traditional Culture Going Out,” Theory Journal, Jinan, no. 2, pp. 124-127, Feb., 2014. (In Chinese)

[6] "Secure a decisive victory in building a moderately prosperous society in all aspects and strive for the great success of socialism with Chinese characteristics for a new era," Report to the 19th National Congress of the Communist Party of China, Beijing, Oct., 2017.

[7] F. Yili, "Reflection on translation and introduction of Chinese minority culture under the background of cultural 'going out' strategy," Contemporary Literary Criticism, Chengdu, no. 3, pp. 151-154, May 2015. (In Chinese) 